\title{
Role of Actin Filament on Synaptic Vesicle Pooling in Cultured Hippocampal Neuron
}

\author{
Se Jeong Lee $^{1, \dagger}$, Hyun-Wook Kim ${ }^{1, \dagger}$, Ji Eun Na ${ }^{1}$, DaSom Kim ${ }^{1}$, \\ Dai Hyun Kim ${ }^{1}$, Jae Ryun Ryu ${ }^{1}$, Woong Sun ${ }^{1}$, Im Joo Rhyu ${ }^{1,2, *}$ \\ ${ }^{1}$ Department of Anatomy, Korea University College of Medicine, Seoul 02841, Korea \\ ${ }^{2}$ Division of Brain Korea 21 Plus Program for Biomedical Science, Korea University College of Medicine, Seoul 02841, Korea
}

\author{
${ }^{\dagger}$ These authors contributed equally to \\ this work. \\ *Correspondence to: \\ Rhyu IJ, \\ (iD) http://orcid.org/0000-0002-5558-6278 \\ Tel: +82-2-2286-1149 \\ Fax: +82-2-929-5696 \\ E-mail: irhyu@korea.ac.kr
}

Received September 22, 2018

Revised October 2, 2018

Accepted October 2, 2018

\begin{abstract}
The synaptic vesicle is a specialized structure in presynaptic terminals that stores various neurotransmitters. The actin filament has been proposed for playing an important role in mobilizing synaptic vesicles. To understand the role of actin filament on synaptic vesicle pooling, we characterized synaptic vesicles and actin filament after treatment of brainderived neurotrophic factor (BDNF) or Latrunculin A on primary cultured neuron from rat embryo hippocampus. Western blots revealed that BDNF treatment increased the expression of synapsin I protein, but Latrunculin A treatment decreased the synapsin I protein expression. The increased expression of synapsin I after BDNF disappeared by the treatment of Latrunculin A. Three-dimensional (3D) tomography of synapse showed that more synaptic vesicles localized near the active zone and total number of synaptic vesicles increased after treatment of BDNF. But the number of synaptic vesicle was 2.5fold reduced in presynaptic terminals and the loss of filamentous network was observed after Latrunculin A application. The treatment of Latruculin A after preincubation of BDNF group showed that synaptic vesicle number was similar to that of control group, but filamentous structures were not restored. These data suggest that the actin filament plays a significant role in synaptic vesicles pooling in presynaptic terminals.
\end{abstract}

Key Words: Synaptic vesicle, Actin filament, Brain-derived neurotrophic factor, Latrunculin A, Electron tomography

\section{INTRODUCTION}

Synapse is the basic unit of neural communication. It is integrated to presynaptic neuron and postsynaptic cell, most nerve conduction is mediated by neurotransmitters, which determine functional nature of the synapses. Synaptic vesicles are located at the presynaptic terminals of neuronal axons and play an important role in chemical neurotransmission (Pechstein \& Shupliakov, 2010; Shupliakov et al., 2011; Südhof, 2012).

Synaptic vesicles are bound to various cytoskeletal proteins including actin filaments. They are connected to each other and it is an essential in the maturation, migration and secretion of synaptic vesicle (Cingolani \& Goda, 2008; Dillon \& Goda,
2005; Doussau \& Augustine, 2000). Many types of proteins that connected to actin in presynaptic terminal have been reported (Bamji et al., 2006; Benfenati et al., 1992). Several steps are required when vesicles move in conjunction with actin (Nelson et al., 2013; Südhof, 2012; Zhang et al., 2003). Researches on the role of actin filaments in docking, priming, fusion and recycling of synaptic vesicles in neuron have long been explored, and molecular, electrophysiological and ultrastructural studies were in action for a long time (Capani et al., 2001; Cottrell et al., 2013; Harlow et al., 2001).

Although there are several hypotheses related to the role of actin in the movement of synaptic vesicles, the actual mechanism has not been understood and further study in ultrastructural level is required.

(a) This is an open-access article distributed under the terms of the Creative Commons Attribution Non-Commercial License (http://creativecommons.org/licenses/by-nc/4.0) which permits unrestricted noncommercial use, distribution, and reproduction in any medium, provided the original work is properly cited.

Copyrights (C) 2018 by Korean Society of Microscopy 
This study focuses on the migration and structural characteristics of synaptic vesicles by western blotting and electron microscopy using primary cultured neurons treated with brain-derived neurotrophic factor (BDNF) and latrunculin A, which is a toxin purified from the red sea sponge Latrunculia magnifica, inhibit actin polymerization (Coué et al., 1987).

\section{MATERIALS AND METHODS}

\section{Cell Culture and Experimental Group}

All experiments in this study were conducted under the Korea University College of Medicine guidelines. Hippocampal neurons were dissected from E18 Sprague-Dawley rat embryos as previously described (Ryu et al., 2016). Briefly, each embryo hippocampi were collected under microscope and dissociated by papain (P-4762; Sigma, USA), incubated in a water bath at $37^{\circ} \mathrm{C}$ for about 20 minutes. After finishing enzyme reaction, trituration and centrifuge step to isolate neuron cells, neuron cells were plated onto poly-D-lysine $(50 \mu \mathrm{g} / \mathrm{mL}, \mathrm{P}-6407$; Sigma) coated $12 \mathrm{~mm}$ glass coverslips in 24 well dishes $\left(5 \times 10^{4}\right.$ cells per well) or 6 well dishes $\left(2 \times 10^{5}\right.$ cells per well). Cells were maintained in Neurobasal medium containing B27, Glutamax, $100 \mathrm{U} / \mathrm{mL}$ penicillin/streptomycin (Gibco, Thermo Scientific, USA) at $37^{\circ} \mathrm{C}$ in a $5 \% \mathrm{CO}_{2}$ humidified atmosphere. The cultured neurons were treated according to experimental design: Group A, control group; Group B, Latruncuin A treatment group; Group C, BDNF treatment group; Group D, La- trunculin A treatment after BDNF pre-incubation group (Fig. 1).

At 14-day in vitro (DIV), BDNF (B-3795; Sigma) was added to culture media for once every 3 days until 21 DIV (final concentration, $10 \mathrm{ng} / \mathrm{mL})$. Latrunculin A $(2.5 \mu \mathrm{M} / \mathrm{mL}, \mathrm{L}-5163$; Sigma) was diluted in media for 16 to 24 hours at 20 DIV. For the treatment of Latrunculin A after BDNF pre-incubation, the neurons were pre-incubated with BDNF until 20 DIV, and then washed by growth media, Latrunculin A was treated till next day. After $21 \mathrm{DIV}$, cell culture was finished and prepared for the next experiment.

\section{Western Blotting}

Neuron cell lysates were prepared using lysis buffer (20-188; Thermo Scientific, Germany) including protease/phosphatase inhibitors (Roche, USA). Protein concentrations were measured using a BCA protein assay kit (Thermo Scientific, USA) and equal amount of protein were separated by $8 \%$ SDSPAGE electrophoresis. Next, gels were transferred onto PVDF membranes (Thermo Scientific), and immunoblotted with primary antibodies diluted 1:1000, overnight at $4^{\circ} \mathrm{C}$. Used antibodies are follows; MAP2 (MAB3418; Millipore, USA), synapsin I (ab8; Abcam, USA), GAPDH (\#2118; Cell Signaling, USA). Antibodies were incubated in horseradish peroxidaseconjugated anti-mouse IgG or anti-rabbit IgG (Cell Signaling) and was analyzed using western blot luminol reagent (sc-2048; Santa Cruz, USA).
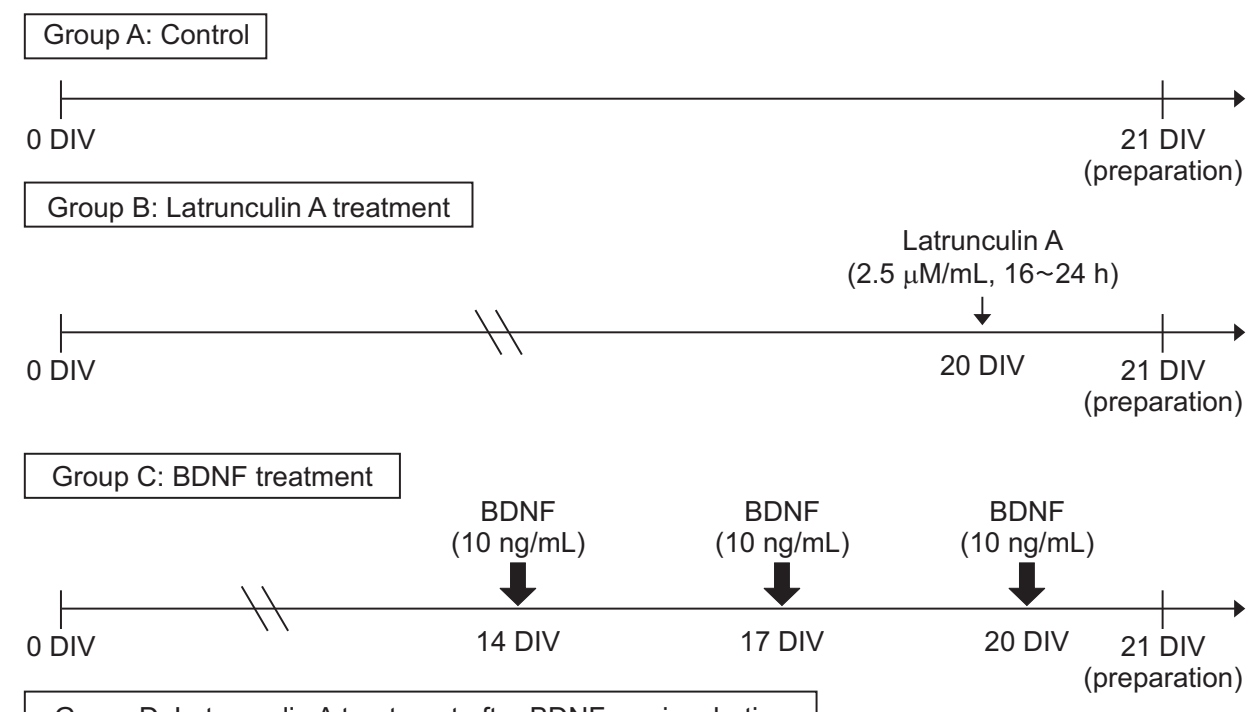

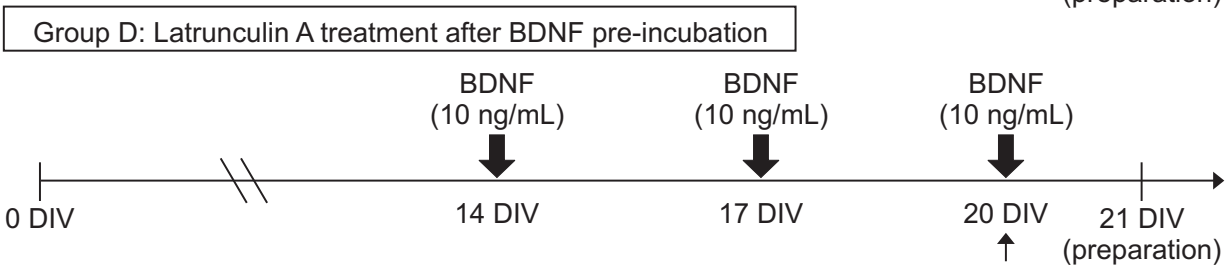

Latrunculin $\mathrm{A}$

$(2.5 \mu \mathrm{M} / \mathrm{mL}, 16 \sim 24 \mathrm{~h})$
Fig. 1. Scheme of the experiment. Control (Group A), Latrunculin A treatment (Group B), brain-derived neurotrophic factor (BDNF) treatment (Group C), Latrunculin A treatment after BDNF preincubation (Group D). DIV, day in vitro. 


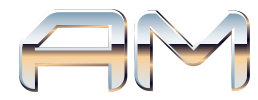

\section{Transmission Electron Microscopy (TEM)}

Neuron cells were prefixed in 2\% paraformaldehyde and 2.5\% glutaraldehyde in $0.1 \mathrm{M}$ phosphate buffer ( $\mathrm{pH}$ 7.4) for 1 hour at room temperature (RT). Each sample was washed with the phosphate buffer 2 times and post-fixed with $1 \%$ osmium tetroxide for 1 hour at RT. En bloc staining was carried out with $0.1 \%$ uranyl acetate in $50 \%$ ethanol for 1 hour to increase the image contrast. Samples were dehydrated through an ascending ethanol series and embedded in an Epon812 (Okenshoji, Japan) mixture and polymerized in a dry oven $\left(65^{\circ} \mathrm{C}, 48 \mathrm{~h}\right)$. Thin sections $(70 \mathrm{~nm})$ were made by using Leica EM UC7 ultra-microtome (Leica Microsystems, Germany), mounted on 200 mesh copper grids, stained with $2 \%$ uranyl acetate and Reynolds lead citrate for $5 \mathrm{~min}$ each, and observed under a Hitachi H-7500 transmission electron microscope (Hitachi, Japan) at an accelerating voltage of $80 \mathrm{kV}$.

\section{Automatic Tomography and Three-Dimensional (3D) Reconstruction}

Automated tomography system was developed from Hitachi's microscopic program as described with minor modification (Kim et al., 2013, 2014). Briefly $150 \mathrm{~nm}$ thickness section was mounted on 200 mesh copper grids and stained with $2 \%$ uranyl acetate for $30 \mathrm{~min}$ and Reynold's lead citrate for $5 \mathrm{~min}$. Grids were loaded into a single specimen holder, the target synapses were searched. Next, the holder was tilts automatically by 2 degree step from $60^{\circ}$ to $-60^{\circ}$, each selected images were recorded automatically. After capturing the image sets were loaded into the EMIP software, the image alignment and back-projection were processed automatically. Serial Z-slice images were imported into IMOD software (version 4.7.15; The University of Colorado, USA) and analyzed. Synaptic structures including synaptic vesicle, post-synaptic density, and actin filament (vesicle tether or linker) were marked in specific color using IMOD program.

\section{Statistical Analysis}

SPSS Statistics 22.0 program (IBM, USA) was used for sta- tistical analysis. Total number of synaptic vesicles, proximal vesicles, tethers and connectors were counted from TEM and 3D images. All data are presented as the standard error of the mean (SEM). The statistical comparisons of groups were performed using the Student's test. Value of $\mathrm{p}<0.05$ were considered to be statistically significant.

\section{RESULTS}

\section{Synapsin I Protein Expression after Treatment of BDNF and/or Latrunculin A}

The synapsin I expression was checked to understand the status of regulation of synaptic vesicles in control, depolymerization by Latrunculin A, and stimulation by BDNF. Expression of synap$\sin \mathrm{I}$ is reduced by actin depolymerization at Group B and D (Fig. 2). Group B's (Latrunculin A treated cell) expression of synapsin I protein was reduced to $80 \%$ or less compared to the control (Fig. 2A and B). When neuron cells were activated by BDNF, the expression of synapsin I was increased (Fig. 2C), which disappeared after the treatment of Latrunculin A (Fig. 2D).

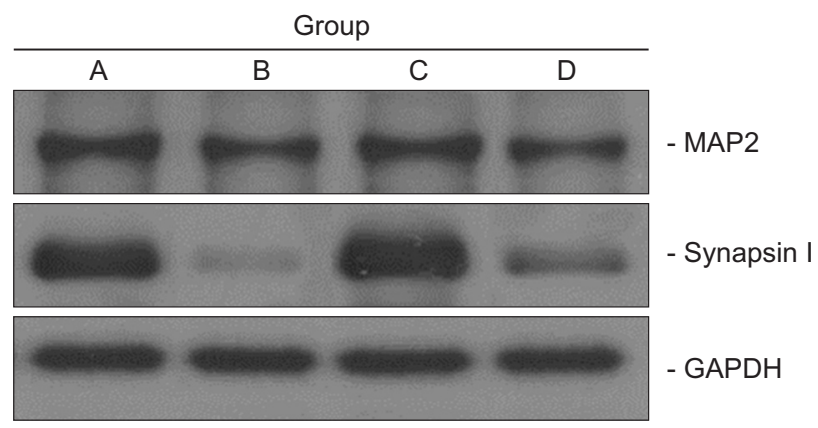

Fig. 2. Western blot of synapsin I expression. Western blot of synapsin I expression in Group A D cells. Each protein was loaded $20 \mu \mathrm{g}$ per well. GAPDH, loading control. Group A, control; Group B, Latrunculin A; Group C, brain-derived neurotrophic factor (BDNF); Group D, BDNF Latrunculin A.

Table 1. Count number of total synaptic vesicles, tethers and connectors

\begin{tabular}{|c|c|c|c|c|c|}
\hline Group & $\begin{array}{c}\text { No. of } \\
\text { synapse }\end{array}$ & $\begin{array}{c}\text { Total no. of } \\
\text { synaptic vesicles }\end{array}$ & $\begin{array}{l}\text { Total no. of proximal } \\
\text { synaptic vesicles }\end{array}$ & $\begin{array}{l}\text { Total no. of } \\
\text { tethers }\end{array}$ & $\begin{array}{l}\text { Total no. of } \\
\text { connectors }\end{array}$ \\
\hline \multirow[t]{2}{*}{ A } & 8 & $2,341^{+t+}$ & $107^{\# \# \#,+t+, \S}$ & $13^{\dagger}$ & $525^{m,++t+}$ \\
\hline & Mean \pm SD & $292.6 \pm 37.6$ & $13.3 \pm 0.8$ & $1.6 \pm 1.9$ & $145 \pm 8.7$ \\
\hline \multirow[t]{2}{*}{ B } & 8 & 1,409 & $8^{* * *,+t+, \$ \S \S}$ & $8^{++\dagger}$ & $145^{* *,+\dagger \dagger}$ \\
\hline & Mean \pm SD & $176.1 \pm 68.6$ & $1 \pm 0.8$ & $1 \pm 0.1$ & $18.1 \pm 3.9$ \\
\hline \multirow[t]{2}{*}{$\mathrm{C}$} & 10 & $4,213^{* * *, * \# \#,+t+1, \$ \varsigma \S}$ & 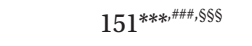 & $33^{*, * \# \#, \$ \varsigma}$ & $920^{* *, \# \# \#, s \$ s}$ \\
\hline & Mean \pm SD & $421 \pm 144.6$ & $15.1 \pm 3.3$ & $3.3 \pm 3.1$ & $92 \pm 36.5$ \\
\hline \multirow[t]{2}{*}{$\mathrm{D}$} & 9 & $2,087^{\dagger++}$ & $59^{*, \ldots \# \#,+十+}$ & $4^{++}$ & $183^{*,+t+}$ \\
\hline & Mean \pm SD & $231.9 \pm 55.6$ & $6.6 \pm 2.8$ & $0.4 \pm 0.8$ & $20.3 \pm 5.3$ \\
\hline
\end{tabular}

Group A, control; Group B, Latrunculin A; Group C, brain-derived neurotrophic factor (BDNF); Group D, BDNF Latrunculin A. 


\section{Synaptic Vesicle Mobilization Is Affected by Actin Polymerization}

The 3D electron tomographic analysis was adopted to understand the synaptic vesicle mobilization after the treatment of
Latrunculin A and/or BDNF. The morphological analysis of electron tomogram was summarized in Table 1.

At first, electron tomogram analysis of synaptic vesicle distribution after Latrunculin A treatment. The number of docked

A
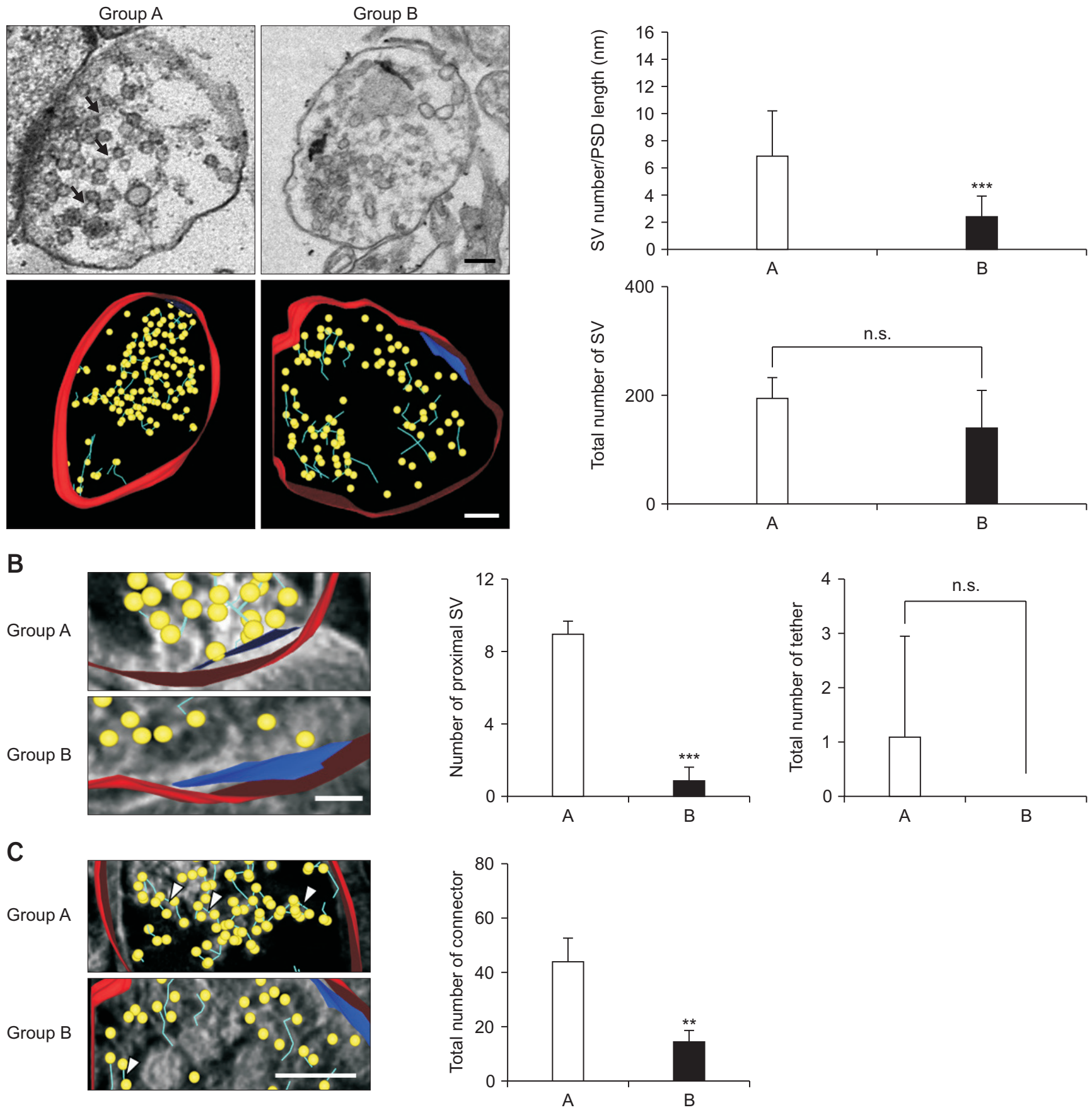

Fig. 3. Structural analysis of group A and B by electron tomography. (A) Electron micrographs (upper) and rendering of synapses (down) of 21 days neuron cells from control (Group A), Latrunculin A treatment (Group B). Average of the number of synaptic vesicles/presynaptic density (active zone) length and total number of synaptic vesicle were calculated and compared with the group A. (B) Average of proximal synaptic vesicle and tethered vesicles per synapse. (C) Average of number of connector. Color list as follows; synapse (red), presynaptic density (PSD, blue), synaptic vesicle (SV, yellow), and actin filament (sea green). ${ }^{* *} \mathrm{p}<0.01,{ }^{* * *} \mathrm{p}<0.001$, vs. group A. n.s., not significant; arrows, synaptic vesicle filament. Scale bars $=200 \mathrm{~nm}$. 
Table 2. Correlative ratio of synaptic vesicle and connector

\begin{tabular}{ccc}
\hline Group & Synaptic vesicle & Connector \\
\hline Group B/A ratio & 0.601 & 0.276 \\
Group D/C ratio & 0.550 & 0.221 \\
\hline
\end{tabular}

Group A, control; Group B, Latrunculin A; Group C, brain-derived neurotrophic factor (BDNF); Group D, BDNF Latrunculin A.

vesicle on active zone at Group B was reduced compared to control ( $\mathrm{p}<0.001$ vs. Group A; Fig. 3A) and synaptic vesicle inside synapse decreased in number and tether (linked to the active zone in synapse), but these changes were not significant (Fig. 3A and B). However, connections per synaptic vesicle showed significant decrease at group B compared to control $(\mathrm{p}<0.01$ vs. Group A; Fig. 3C). Comparing of group A and B's synaptic vesicle number by ratio, synaptic vesicle of group B was $60 \%$ of control group and number of connectors was $27 \%$ of control (Table 2 ).

The effect of BDNF on the synaptic vesicles mobilization and its reversal effect after Latrunculin A were analyzed. The BDNF treatment increased the number of synaptic vesicles, proximal synaptic vesicles, and interconnectors (Fig. 4). The increased number of each parameters was significantly lowered after Latrunculin A. According to the treatment, the number of docked vesicle, total vesicle per synapse and average connection between them showed decrease in group $\mathrm{D}$ compared to group C ( $<<0.01, \mathrm{p}<0.001$ vs. Group C; Fig. 4). Group D's synaptic vesicles were $55 \%$ compared to group C and connections were reduced to $22 \%$ (Table 2 ). Therefore, this study indicates that suppression of actin synthesis breaks synaptic vesicle's co-link formation and decreases the synaptic vesicle recycle ratio as well.

\section{DISCUSSION}

Synapses create, receive, and transport electrical signals to target cells through neurotransmitters (Shupliakov et al., 2011; Südhof, 2012). Fusion of neurotransmitter stored in synaptic vesicles affects a remarkable area of the pre-synaptic membrane (Greengard et al., 1993; Michel et al., 2015). Synaptic vesicle's life cycle is composed of docking, priming, fusion and recycle and this cycle is regulated by environmental condition and various stimulus (Greengard et al., 1993; Michel et al., 2015; Rizzoli \& Betz, 2005).

The actin filaments are mainly located in presynaptic terminal and participate in the vesicle recycle maintenance and regulation (Cingolani \& Goda, 2008; Dillon \& Goda, 2005; Doussau \& Augustine, 2000). The actin connects synaptic vesicles with the active zones and surrounds the vesicles at a reserve pool (Dillon \& Goda, 2005). The actin at an active zone is reported to guide docking of arriving vesicle while it also regulates releasable pool (Bloom et al., 2003; Cingolani \& Goda, 2008; Haucke et al., 2011; Rizzoli \& Betz, 2005). However, there are controversies about relations between the actin and synaptic transmission. Some studies show synaptic vesicle mobilization and recycling are closely related, while some suspects negative regulatory role or facilitator role, also other reports tells that there is no relation between the vesicle recycling (Cole et al., 2000; Morales et al., 2000; Richards et al., 2004; Shupliakov et al., 2002).

In this study, reduced synapsin I is expressed in all Latrunculin A treated neuron cells. The synapsin is thought to be involved in regulating the number of synaptic vesicles available for release via exocytosis at any one time (Bloom et al., 2003; Jovanovic et al., 2000). This data imply that the synaptic vesicle mobilization is affected by BDNF and Latrunculin A, which was confirmed through electron tomographic investigation.

The electron tomographic data showed that Latrunculin A alone did not cause significant change in total synaptic vesicle and tether number compared to control. But, the number of proximal synaptic vesicle number and total number of connector were significantly decreased in Latrunculin A treated group. This blocking polymerization of actin filament influenced the synaptic vesicles population in readily releasable zone, although the overall number of synaptic vesicle was not affected.

The samples treated with BDNF showed significant increase of the number of synaptic vesicles, proximal synaptic vesicle number, tethering, and connector. BDNF is a neurotropic factor located at CNS that increases docking of synaptic vesicle number and recycling number when enhanced. In addition, the neurotransmitter release and vesicle numbers were reported to increase (Sanchez et al., 2006; Shinoda et al., 2014), which is supported by these experimental data. However, these active morphological data are diminished after actin depolymerization. By suppressing actin polymerization in BDNF treated neuron cells, the total number of vesicle, tether, and connectors all showed decrease.

Our results show that actin is not only guiding synaptic vesicles but also linking each vesicle together. As there are some arguments about the interactions between actin and synaptic vesicle, this study support the hypothesis that actin filament affects the synaptic vesicle pooling.

\section{SUMMARY}

In this study, the role of actin filament in the synaptic vesicle pooling was investigated with cultured hippocampal neurons based on neuronal stimulatory agent treatment and actin polymerization blocker. The experimental results present that the actin polymerization is an important synaptic pooling mobilization. 
A
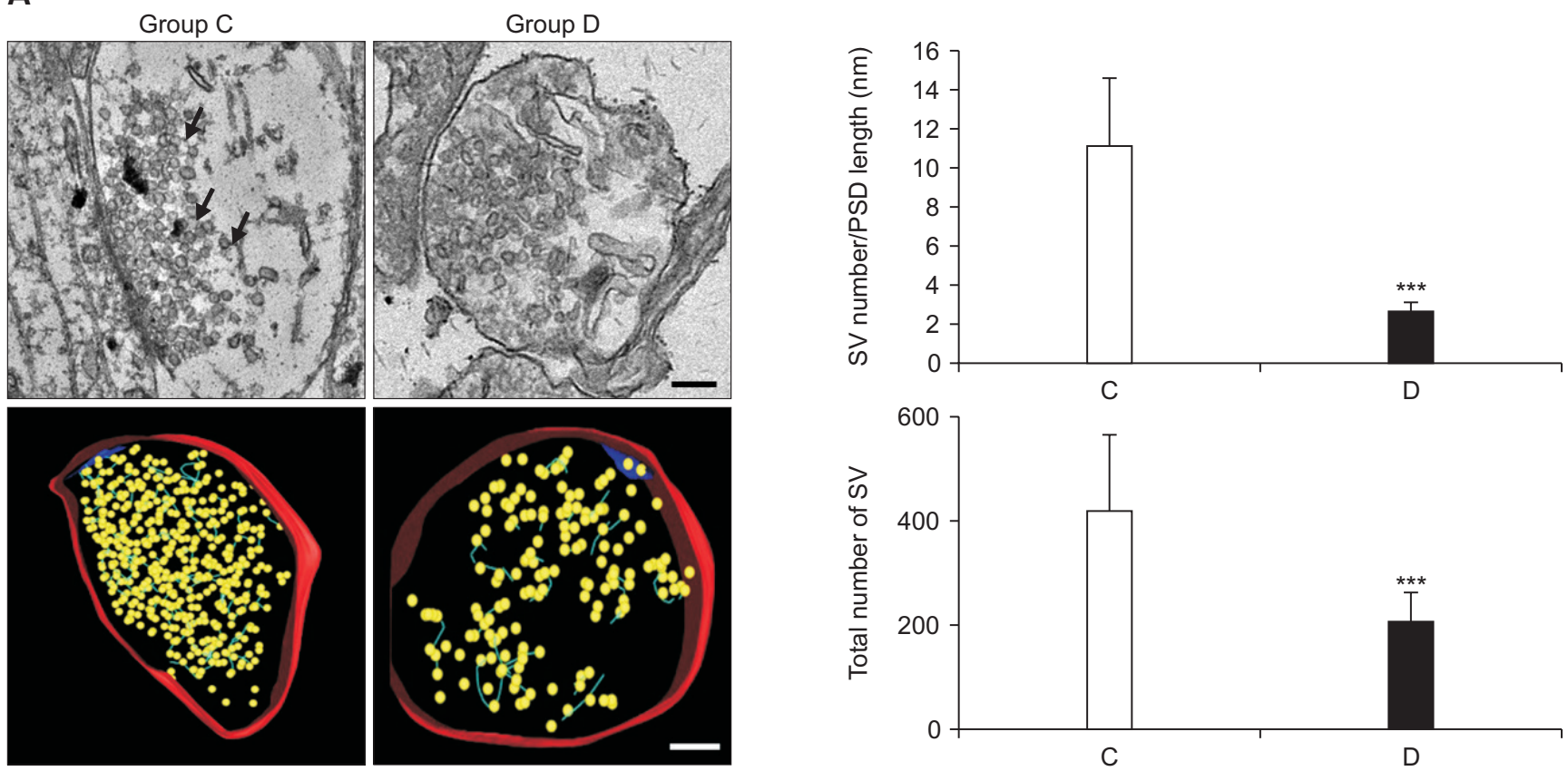

B

Group C
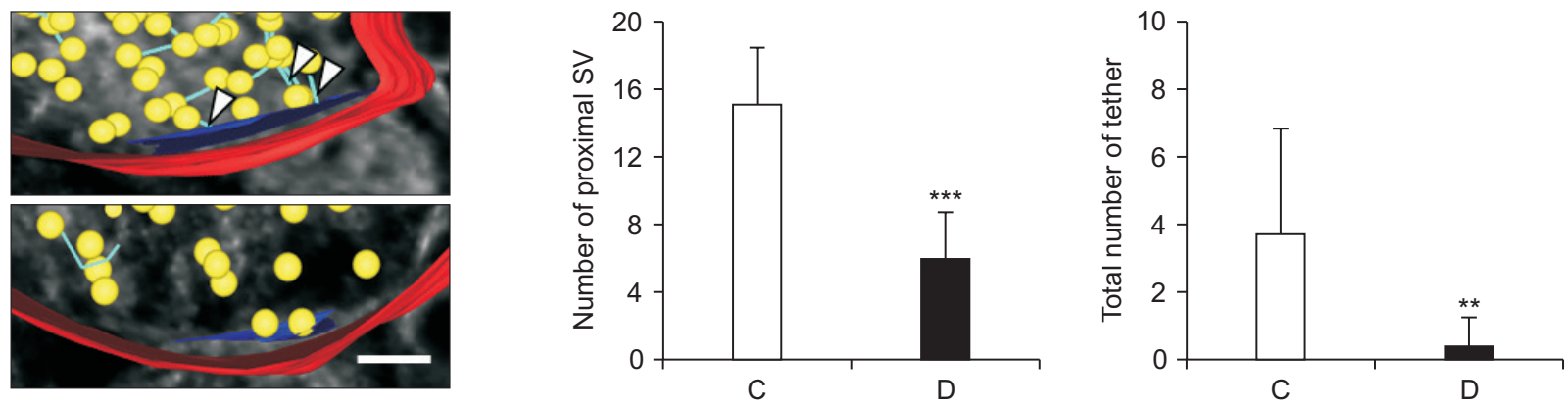

C

Group C
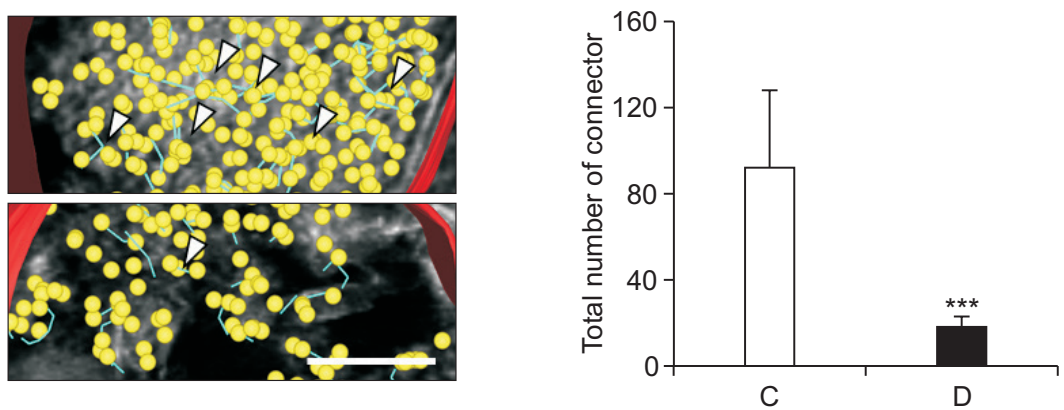

Fig. 4. Structural analysis of group $\mathrm{C}$ and $\mathrm{D}$ by electron tomography. (A) Electron micrographs (upper) and rendering of synapses (down) of 21 days neuron cells from brain-derived neurotrophic factor (BDNF) treatment (Group C), Latrunculin A treatment after BDNF pre-incubation (Group D). Average of the number of synaptic vesicles/presynaptic density (active zone) length and total number of synaptic vesicle were calculated and compared with the group C. (B) Average of proximal synaptic vesicle and tethered vesicles per synapse. (C) Average of number of connector. Color list as follows; synapse (red), presynaptic density (PSD, blue), synaptic vesicle (SV, yellow), and actin filament (sea green). ${ }^{* *} \mathrm{p}<0.01,{ }^{* * *} \mathrm{p}<0.001$, vs. group C. Arrows; synaptic vesicle filament. Scale bars $=200 \mathrm{~nm}$.

\section{CONFLICT OF INTEREST}

No potential conflict of interest relevant to this article was reported.

\section{ACKNOWLEDGMENTS}

This work was supported by Basic Science Research Program through the National Research Foundation (NRF-2013R1A1A2060344). 


\section{REFERENCES}

Bamji S X, Rico B, Kimes N, and Reichardt L F (2006) BDNF mobilizes synaptic vesicles and enhances synapse formation by disrupting cadherin-beta-catenin interactions. J. Cell Biol. 174, 289-299.

Benfenati F, Valtorta F, Chieregatti E, and Greengard P (1992) Interaction of free and synaptic vesicle-bound synapsin I with F-actin. Neuron $\mathbf{8}$, 377-386.

Bloom O, Evergren E, Tomilin N, Kjaerulff O, Löw P, Brodin L, Pieribone VA, Greengard P, and Shupliakov $O$ (2003) Colocalization of synapsin and actin during synaptic vesicle recycling. J. Cell Biol. 161, 737-747.

Capani F, Martone M E, Deerinck T J, and Ellisman M H (2001) Selective localization of high concentrations of F-actin in subpopulations of dendritic spines in rat central nervous system: a three-dimensional electron microscopic study. J. Comp. Neurol. 435, 156-170.

Cingolani L A and Goda Y (2008) Actin in action: the interplay between the actin cytoskeleton and synaptic efficacy. Nat. Rev. Neurosci. 9, 344-356.

Cole A A, Chen X, and Reese T S (2016) A network of three types of filaments organizes synaptic vesicles for storage, mobilization, and docking. J. Neurosci. 36, 3222-3230.

Cole J C, Villa B R, and Wilkinson R S (2000) Disruption of actin impedes transmitter release in snake motor terminals. J. Physiol. 525, 579586.

Cottrell J R, Levenson J M, Kim S H, Gibson H E, Richardson K A, Sivula M, Li B, Ashford C J, Heindl K A, Babcock R J, Rose D M, Hempel C M, Wiig K A, Laeng P, Levin M E, Ryan T A, and Gerber D J (2013) Working memory impairment in calcineurin knock-out mice is associated with alterations in synaptic vesicle cycling and disruption of high-frequency synaptic and network activity in prefrontal cortex. J. Neurosci. 33, 10938-10949.

Coué M, Brenner SL, Spector I, and Korn ED (1987) Inhibition of actin polymerization by latrunculin A. FEBS Lett. 213, 316-318.

Dillon C and Goda Y (2005) The actin cytoskeleton: integrating form and function at the synapse. Annu. Rev. Neurosci. 28, 25-55.

Doussau F and Augustine G J (2000) The actin cytoskeleton and neurotransmitter release: an overview. Biochimie 82, 353-363.

Greengard P, Valtorta F, Czernik A J, and Benfenati F (1993) Synaptic vesicle phosphoproteins and regulation of synaptic function. Science 259, 780-785.

Harlow M L, Ress D, Stoschek A, Marshall R M, and McMahan U J (2001) The architecture of active zone material at the frog's neuromuscular junction. Nature 409, 479-484.

Haucke V, Neher E, and Sigrist S J (2011) Protein scaffolds in the coupling of synaptic exocytosis and endocytoisis. Nat. Rev. Neurosci. 12, 127-138.

Jovanovic J N, Czernik A J, Fienberg A A, Greengard P, and Sihra T S (2000) Synapsins as mediators of BDNF-enhanced neurotransmitter release. Nat. Neurosci. 3, 323-329.
Kim H W, Kim D, and Rhyu I J (2014) Electron tomography and synapse study. Appl. Microsc. 44, 83-87.

Kim H W, Oh S H, Kim N, Nakazawa E, and Rhyu I J (2013) Rapid method for electron tomographic reconstruction and three-dimensional modeling of the murine synapse using an automated fiducial marker-free system. Microsc. Microanal. 19, 182-187.

Michel K, Müller J A, Oprişoreanu A M, and Schoch S (2015) The presynaptic active zone: a dynamic scaffold that regulates synaptic efficacy. Exp. Cell Res. 335, 157-164.

Morales M, Colicos M A, and Goda Y (2000) Actin-dependent regulation of neurotransmitter release at central synapses. Neuron 27, 539550.

Nelson J C, Stavoe A K, and Colón-Ramos D A (2013) The actin cytoskeleton in presynaptic assembly. Cell Adh. Migr. 7, 379-387.

Pechstein A and Shupliakov O (2010) Taking a back seat: synaptic vesicle clustering in presynaptic terminals. Front. Synaptic Neurosci. 15, 143.

Richards D A, Rizzoli S O, and Betz W J (2004) Effects of wortmannin and latrunculin $A$ on slow endocytosis at the frog neuromuscular junction. J. Physiol. 557, 77-91.

Rizzoli S 0 and Betz W J (2005) Synaptic vesicle pools. Nat. Rev. Neurosci. 6, 57-69.

Ryu J R, Jang M J, Jo Y, Joo S, Lee D H, Lee B Y, Nam Y, and Sun W (2016) Synaptic compartmentalization by micropatterned masking of a surface adhesive cue in cultured neurons. Biomaterials 92, 46-56.

Sanchez A L, Matthews B J, Meynard M M, Hu B, Javed S, and Cohen Cory S (2006) BDNF increases synapse density in dendrites of developing tectal neurons in vivo. Development 133, 2477-2486.

Shinoda Y, Ahmed S, Ramachandran B, Bharat V, Brockelt D, Altas B, and Dean C (2014) BDNF enhances spontaneous and activity-dependent neurotransmitter release at excitatory terminals but not at inhibitory terminals in hippocampal neurons. Front. Synaptic Neurosci. 6, 1-12.

Shupliakov O, Bloom O, Gustafsson J S, Kjaerulff O, Low P, Tomilin N, Pieribone V A, Greengard P, and Brodin L (2002) Impaired recycling of synaptic vesicles after acute perturbation of the presynaptic actin cytoskeleton. Proc. Natl. Acad. Sci. U S A 99, 14476-14481.

Shupliakov O, Haucke V, and Pechstein A (2011) How synapsin I may cluster synaptic vesicles. Semin. Cell Dev. Biol. 22, 393-399.

Südhof T C (2012) The presynaptic active zone. Neuron 75, 11-25.

Yarmola E G, Somasundaram T, Boring T A, Spector I, and Bubb M R (2000) Actin-latrunculin A structure and function. Differential modulation of actin-binding protein function by latrunculin A. J. Biol. Chem. 275, 28120-28127.

Zhang W and Benson D L (2001) Stages of synapse development defined by dependence on F-actin. J. Neurosci. 21, 5169-5181. 